\title{
Neural Dynamics in Primate Cortex during Exposure to Subanesthetic Concentrations of Nitrous Oxide
}

\author{
(1)Matthew S. Willsey, ${ }^{1,2, *}$ Chrono S. Nu, ${ }^{2, *}$ Samuel R. Nason, ${ }^{2}$ Karen E. Schroeder, ${ }^{3}$ Brianna C. Hutchison, ${ }^{2}$ \\ Elissa J. Welle, ${ }^{2}$ Parag G. Patil,, ${ }^{1,2,4,5}$ George A. Mashour, ${ }^{1,4,5,6, *}$ and Cynthia A. Chestek ${ }^{2,4,6,7,8, *}$
}

\section{https://doi.org/10.1523/ENEURO.0479-20.2021}

${ }^{1}$ Department of Neurosurgery, University of Michigan, Ann Arbor, Michigan 48109, ${ }^{2}$ Department of Biomedical Engineering, University of Michigan, Ann Arbor, Michigan 48109, ${ }^{3}$ Department of Neuroscience, Columbia University, New York, New York 10027, ${ }^{4}$ Neuroscience Graduate Program, University of Michigan Medical School, Ann Arbor, Michigan 48109, ${ }^{5}$ Department of Anesthesiology, University of Michigan, Ann Arbor, Michigan 48109, ${ }^{6}$ Center for Consciousness Studies, University of Michigan, Ann Arbor, Michigan 48109, ${ }^{7}$ Department of Electrical Engineering and Computer Science, University of Michigan, Ann Arbor, Michigan 48109, and ${ }^{8}$ Robotics Graduate Program, University of Michigan, Ann Arbor, Michigan 48109

\begin{abstract}
Nitrous oxide $\left(\mathrm{N}_{2} \mathrm{O}\right)$ is a hypnotic gas with antidepressant and psychedelic properties at subanesthetic concentrations. Despite long-standing clinical use, there is insufficient understanding of its effect on neural dynamics and cortical processing, which is important for mechanistic understanding of its therapeutic effects. We administered subanesthetic $(70 \%)$, inhaled $\mathrm{N}_{2} \mathrm{O}$ and studied the dynamic changes of spiking rate, spectral content, and somatosensory information representation in primary motor cortex (M1) in two male rhesus macaques implanted with Utah microelectrode arrays in the hand area of M1. The average sorted multiunit spiking rate in $\mathrm{M} 1$ increased from $8.1 \pm 0.99$ to $10.6 \pm 1.3 \mathrm{~Hz}$ in Monkey $\mathrm{W}(p<0.001)$ and from $5.6 \pm 0.87$ to $7.0 \pm 1.1 \mathrm{~Hz}$ in Monkey $\mathrm{N}(p=0.003)$. Power spectral densities increased in beta- and gamma-band power. To evaluate somatosensory content in M1 as a surrogate of information transfer, fingers were lightly brushed and classified using a naive Bayes classifier. In both monkeys, the proportion of correctly classified fingers dropped from $0.50 \pm 0.06$ before $\mathrm{N}_{2} \mathrm{O}$ inhalation to $0.34 \pm 0.03$ during $\mathrm{N}_{2} \mathrm{O}$ inhalation $(p=0.018)$, although some fingers continued to be correctly classified $(p=0.005)$. The decrease in correct classifications corresponded to decreased modulation depth for the population $(p=0.005)$ and fewer modulated units $(p=0.046)$. However, the increased single-unit firing rate was not correlated with its modulation depth $\left(R^{2}<0.001\right.$, $p=0.93$ ). These data suggest that $\mathrm{N}_{2} \mathrm{O}$ degrades information transfer, although no clear relationship was found between neuronal tuning and $\mathrm{N}_{2} \mathrm{O}$-induced changes in firing rate.
\end{abstract}

Key words: anesthesia; consciousness; nitrous oxide; NMDA antagonist; sensorimotor

\section{Significance Statement}

There are few intracortical studies characterizing the influence of nitrous oxide $\left(\mathrm{N}_{2} \mathrm{O}\right)$ on neuronal behavior in the primate brain. Herein we demonstrate increased spiking rate in primary motor cortex (M1) as well as increased beta/gamma power during the administration of subanesthetic $\mathrm{N}_{2} \mathrm{O}$. In a previously validated model of primary somatosensory to M1 information transfer, we also show a degradation of somatosensory representation. The degraded representation, as assessed by modulation depth, was not correlated with neuronal firing rate changes.

Received November 4, 2020; accepted May 31, 2021; First published June 16, 2021.

The authors declare no competing financial interests.
Author contributions: M.S.W., C.S.N., S.R.N., K.E.S., P.G.P., G.A.M., and C.A.C. designed research; M.S.W., C.S.N., S.R.N., B.C.H., E.J.W., P.G.P., and C.A.C. performed research; M.S.W., C.S.N., S.R.N., and K.E.S. contributed unpublished reagents/analytic tools; M.S.W., C.S.N., G.A.M., and C.A.C. analyzed data; M.S.W., G.A.M., and C.A.C. wrote the paper. 


\section{Introduction}

Nitrous oxide $\left(\mathrm{N}_{2} \mathrm{O}\right)$ and ketamine are unique anesthetics with antidepressant (Tadler and Mickey, 2018) and psychedelic (Icaza and Mashour, 2013) effects at subanesthetic concentrations. Unlike canonical general anesthetics, they are thought to (1) act by antagonizing glutamatergic NMDA receptors (Thomson et al., 1985; Jevtović-Todorović et al., 1998) rather than through the potentiation of GABAergic transmission; (2) increase cerebral metabolism (Takeshita et al., 1972; Deutsch and Samra, 1990); (3) enhance highfrequency electroencephalographic activity (Rampil et al., 1998; Lee et al., 2013; Akeju et al., 2016); and (4) increase cortical cholinergic tone (Shichino et al., 1998; Pal et al., 2015). There has been a recent focus on how large-scale brain networks are modulated by general anesthetics in terms of functional connectivity, dynamics, and graph-theoretical variables (Cao et al., 2018; Huang et al., 2018; Lee and Mashour, 2018); however, there is a paucity of mesoscopic network data for ketamine and $\mathrm{N}_{2} \mathrm{O}$. Analysis of local cortical networks during $\mathrm{N}_{2} \mathrm{O}$ exposure may provide better understanding of the mechanism responsible for the psychedelic, analgesic, and antidepressive properties and may also inform therapeutic strategies.

Neural firing rate, cortical oscillations, and information transfer in nonhuman primate cortex during exposure to anesthetic concentrations of ketamine have previously been characterized (Schroeder et al., 2016). This study investigates the effects of $\mathrm{N}_{2} \mathrm{O}$ on neuronal spiking rate and high-frequency content of local field potentials (LFPs) in primary motor cortex (M1) of the nonhuman primate brain. Furthermore, previous animal studies suggest that somatosensory afferents from somatosensory cortex (S1) mediate transfer of information to $M 1$, where sensory content is represented (Andersson, 1995; Farkas et al., 1999; Mao et al., 2011). Thus, to evaluate the effect of $\mathrm{N}_{2} \mathrm{O}$ on sensory representation in $\mathrm{M} 1$, we measured the somatosensory content in M1 during a finger-brushing task. Somatosensory content in M1 can serve as a surrogate of cortical information transfer during exposure to NMDA antagonists such as $\mathrm{N}_{2} \mathrm{O}$, because content in $\mathrm{S} 1$ has been shown to be preserved (reflecting intact thalamocortical information transfer) during anesthetic doses of ketamine while content in M1 was disrupted (reflecting impaired corticocortical information transfer; Schroeder et al., 2016).

This work was funded by National Institutes of Health (NIH) Grant R01-GM111293. M.S.W. was partially supported by NIH Grant T32-NS-007222. P.G.P. was supported by the A. Alfred Taubman Medical Research Institute.

*M.S.W., C.S.N., G.A.M., and C.A.C. contributed equally to this work.

We thank Eric Kennedy for animal training/care, and Tom Cichonski for editorial comments.

Correspondence should be addressed to George A. Mashour at gmashour@ umich.edu or Cynthia A. Chestek at cchestek@umich.edu.

https://doi.org/10.1523/ENEURO.0479-20.2021

Copyright (C) 2021 Willsey et al.

This is an open-access article distributed under the terms of the Creative Commons Attribution 4.0 International license, which permits unrestricted use, distribution and reproduction in any medium provided that the original work is properly attributed.

\section{Materials and Methods}

\section{Surgical procedure}

Experimental protocols were approved by the authors' Institutional Animal Care and Use Committee. Two male rhesus macaques, Monkey $\mathrm{W}$ and Monkey $\mathrm{N}$, were implanted with Utah Arrays with electrode lengths of $1.5 \mathrm{~mm}$ (Blackrock Microsystems) in M1 using methods previously described (Schroeder et al., 2016). Monkey W was implanted with two 96-channel Utah Arrays, with one in $\mathrm{M} 1$ and one in S1. Monkey $\mathrm{N}$ was implanted in left $\mathrm{M} 1$ with two $8 \times 8$ electrode split arrays (where the anterior array was used in this analysis) and one 96-channel array in S1. Because of exposure, the wire bundle connected to the posterior array of Monkey $\mathrm{N}$ was cut, which eliminated the signal from 64 of the channels. Because of this damage, Monkey $\mathrm{N}$ was eventually reimplanted in the contralateral (right) cortex with two split $8 \times 8$ electrode arrays in $\mathrm{M} 1$ and one 96-electrode array in S1, shown in Figure $1 A$. There were no clinically significant adverse events in addition to wound revision surgeries for exposed hardware from a receding wound edge during healing.

\section{Experimental setup and $\mathrm{N}_{2} \mathrm{O}$ administration}

Three tests were performed on $3 d$, separated by several months, for each nonhuman primate: one for Monkey $\mathrm{W}$, one for the left implant of Monkey N (day 1 of Monkey $\mathrm{N}$ ), and one for the right implant of Monkey $\mathrm{N}$ (day 2 of Monkey $\mathrm{N}$ ). The macaques were trained to sit in a monkey chair [Crist Instrument (http://www.cristinstrument.com)], with their head secured in customized titanium posts (Crist Instrument), while their Utah Arrays were connected to a neural signal processor (Cerebus Neural Processing System, Blackrock Microsystems) and their arms were secured in acrylic restraints. The monkeys were also trained to tolerate finger brushings without agitation. Using a cotton-tip applicator, individual fingers were manually brushed without skin indentation at a $2 \mathrm{~Hz}$ rate timed to a metronome. The fingers brushed during a given trial were randomly selected by a computer running XPC Target (MathWorks) and displayed on a monitor to prompt the experimenters. Brushings were conducted for $5 \mathrm{~s}$, and the first $2 \mathrm{~s}$ were discarded from the analysis given that the experimenters switched fingers during the first $2 \mathrm{~s}$ of each trial. Given the desire for only sensory information in motor cortex, trials in which the monkey moved spontaneously were noted and later discarded from the analysis. See Schroeder et al. (2016) for further details and illustrations regarding the experimental setup.

A semiclosed Mapleson A breathing circuit delivered $70 \% \mathrm{~N}_{2} \mathrm{O}$ at a continuous rate via sealed face mask secured snuggly around the head with an elastic band. Monkey W was gradually acclimated to the mask over several sessions with rewards. Monkey $\mathrm{N}$ tolerated the mask on the first day of training. The face mask was placed 10-20 min before $\mathrm{N}_{2} \mathrm{O}$ administration to allow the monkey to become comfortable with the face mask system. On day 1 for Monkey $\mathrm{W}$ before $\mathrm{N}_{2} \mathrm{O}$ administration, the classification of finger brushings was compared for room air and $100 \%$ oxygen via sealed face mask, and no 
A

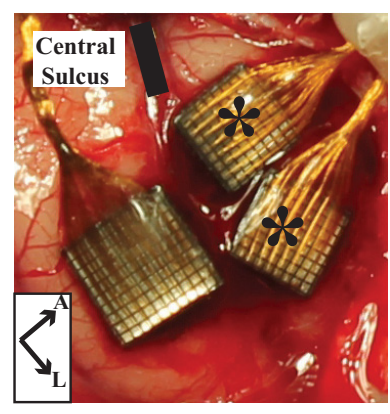

B

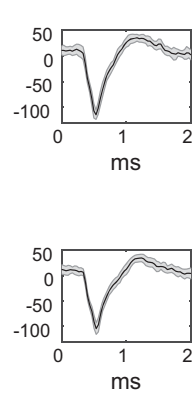

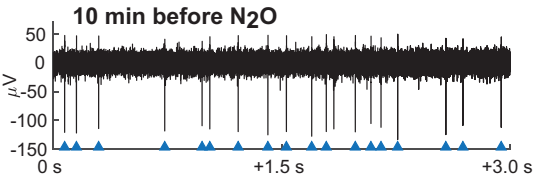

15 min into $\mathrm{N}_{2} \mathrm{O}$

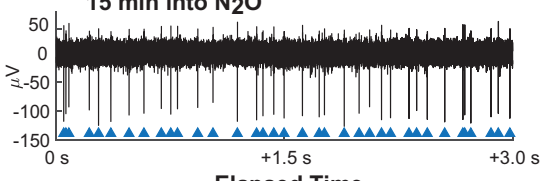

Elapsed Time
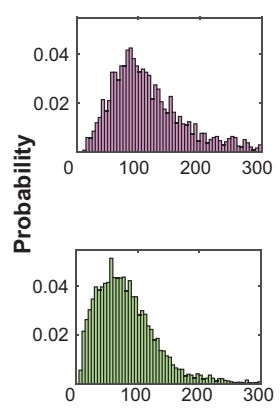

ISI (ms)

C

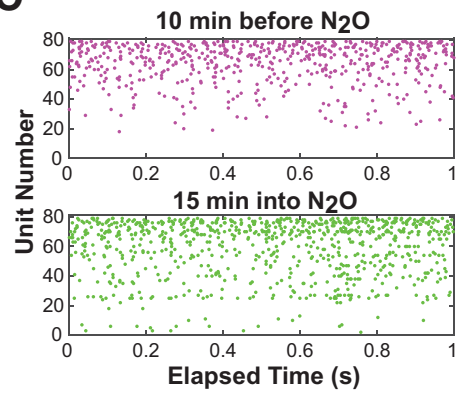

D

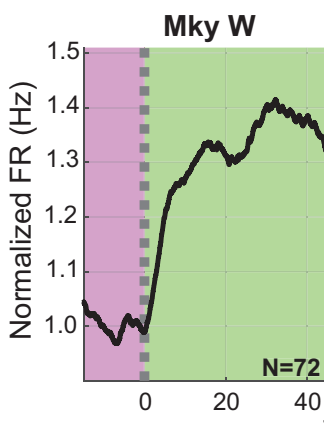

Mky N, L Cortex

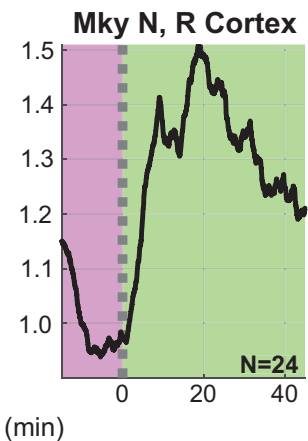

E

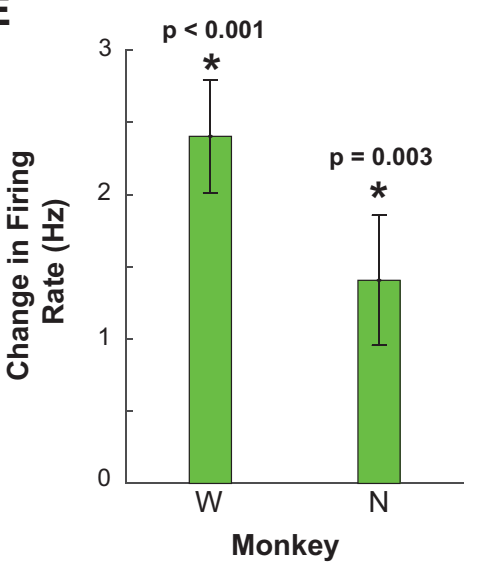

$\mathbf{F}$

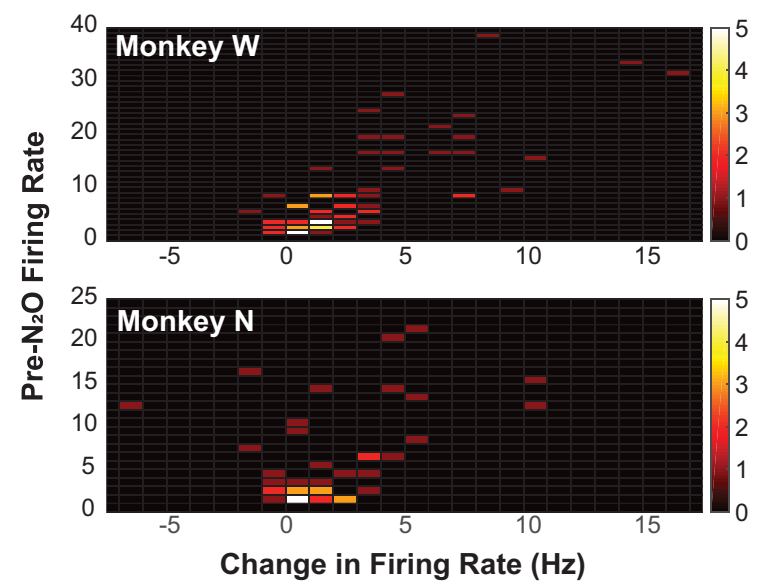

Figure 1. The influence of nitrous oxide on spiking rate. $\boldsymbol{A}$, Image of the implanted arrays in primary motor cortex. Central sulcus is indicated with a solid black line, and asterisks denote the split motor arrays used in this analysis. The sensory array was not analyzed. The legend at the bottom indicates the anterior direction $(A)$ and the lateral direction $(L)$. $B$, The single-unit insets on the left show the mean (in black) and SD (in gray) for spike waveforms from 15 to 5 min before $\mathrm{N}_{2} \mathrm{O}$ initiation (top) and from 10 to 20 min after $\mathrm{N}_{2} \mathrm{O}$ initiation (bottom), and indicate waveform stability before and during $\mathrm{N}_{2} \mathrm{O}$. The $y$-axis of the inset is reported in microvolts. In the middle panel, the raw data from channel 25 shows discriminated single units at 10 min before $\mathrm{N}_{2} \mathrm{O}$ administration (top) and 15 min after beginning continuous $\mathrm{N}_{2} \mathrm{O}$ administration (bottom). The raw data depict increased spiking rate for this channel. The blue triangles indicate the time of an action potential. On the right, spike-interval histograms show the distribution of the interspike interval of the period 10-20 min before $\mathrm{N}_{2} \mathrm{O}$ (top, magenta) and 10-20 min after $\mathrm{N}_{2} \mathrm{O}$ (bottom, green). The area of histograms sums to unity. C, The $1 \mathrm{~s}$ raster of Monkey W plot for 1 min before (pre- $\mathrm{N}_{2} \mathrm{O}$, purple) and 15 min after (green) the start of $\mathrm{N}_{2} \mathrm{O}$ administration is given to illustrate representative results. $\boldsymbol{D}$, The trend of spiking rate is depicted for each monkey for pre- $\mathrm{N}_{2} \mathrm{O}$ state (purple region) and continuous $\mathrm{N}_{2} \mathrm{O}$ administration (green region). The spiking rate is normalized by the baseline firing rate before $\mathrm{N}_{2} \mathrm{O}$ administration. The pre- $\mathrm{N}_{2} \mathrm{O}$ baseline firing rate was $8.1 \mathrm{~Hz}$ for Monkey $\mathrm{W}, 4.7 \mathrm{~Hz}$ for the left cortex of Monkey $\mathrm{N}$, and $6.4 \mathrm{~Hz}$ for the right cortex of Monkey $\mathrm{N}$. The number of sorted multiunits for each day, $N$, is indicated with each subplot. The dashed lines indicate when $\mathrm{N}_{2} \mathrm{O}$ was initiated. $\boldsymbol{E}$, The bar plot depicts the change in spiking rate when combining both days for Monkey W and Monkey $\mathrm{N}$. 
continued

There is a statistically significant increase in spiking rate for both monkeys, as indicated by the asterisk $(p<0.001$ for Monkey W and $p=0.003$ for Monkey N). $\boldsymbol{F}$, The two-dimensional histograms illustrate the number of multiunits with the change in firing rate during $\mathrm{N}_{2} \mathrm{O}$ (on the $x$-axis) and the pre- $\mathrm{N}_{2} \mathrm{O}$ firing rate (on the $y$-axis). The actual number of multiunits is color coded with the legend to the right of the panel. For both Monkey W (top) and Monkey N (bottom), the histogram is shifted to the right.

significant differences in correct classification of finger brushings were found. This test was not performed on day 2 for Monkey $\mathrm{N}$.

During $\mathrm{N}_{2} \mathrm{O}$ delivery, the monkeys were monitored under direct observation by a laboratory technician, trained graduate student, or physician. During $\mathrm{N}_{2} \mathrm{O}$ administration, monkeys remained awake and cooperative; heart rate and respiratory rate were checked every $15 \mathrm{~min}$. During the final day with Monkey $\mathrm{N}$, only the respiratory rate was monitored to avoid physical contact with the primate, which led to uncooperative behavior. Respiratory rate remained adequate (always $>32$ breaths $/ \mathrm{min}$ ) throughout the experiments. After $\mathrm{N}_{2} \mathrm{O}$ administration, $100 \% \mathrm{O}_{2}$ was administered for $5 \mathrm{~min}$, and monitoring was continued for an additional $15 \mathrm{~min}$ after the cessation of supplemental oxygen. The monkeys remained awake and did not lose consciousness, as evidenced by widely open eyes and a normal frequency of motor movements and conjugate eye movements. There were no adverse events related to $\mathrm{N}_{2} \mathrm{O}$ administration.

\section{Front-end processing-analog to cleaned multiunits}

The output from the Utah Array was processed in two distinct formats. The first data stream was the raw signal sampled at $30 \mathrm{kHz}$. This broadband data stream was used for the spectral analysis described below. The second data stream was the time stamp of all recorded spikes for all channels. Spikes were defined using the Cerebus neural signal processor (Blackrock Microsystems) when the 250 $\mathrm{Hz}$ high-pass-filtered signal crossed a threshold of -4.5 times the root mean square voltage. The Cerebus system then communicated the detection of a spike to a computer running customized software in the XPC Target environment (MathWorks). The XPC Target computer logged the timestamp of the received spike in $1 \mathrm{~ms}$ time bins. This structure allowed the replay of experimental spikes offline as well as trial-by-trial organization that will be discussed in subsequent sections.

In some analyses described below, sorted units were required. Spikes were sorted using Offline Sorter (Plexon). Sorted clusters were scored with a number between 1 and 4 . The principal components of threshold-crossing events were calculated and displayed in a two-dimensional space. Sorted units with a score of 4 correspond to when the principal components of the cluster do not overlap with other threshold-crossing events; a score of 3 , to clusters with little overlap with other clusters; a score of 2 , nonclusters and a morphologic bipolar spike in the time domain; and a score of 1 , the remaining threshold-crossing events. Sorted units with a score of 1 were excluded, those with a score of 2 were considered sorted multiunits, and those with scores of 3 and 4 were considered isolated single units.
Because we wanted to include neural information from the hash unit, all threshold-crossing events were used for population-based decoding analysis and for calculating the modulation depth. These unsorted multiunits were reviewed by eye, and channel waveforms that were not consistent with a neuronal action potential were removed from the analysis.

Removing data at times of motor movement was a multistep process. First, during finger-brushing trials, times of movement were flagged by experimenters, and these data were not included in the subsequent analysis. Second, using an automated program, any finger-brushing trial was removed if $\geq 30$ channels recorded a spike in the same $1 \mathrm{~ms}$ bin, as this high level of activity was not consistent with a motionless monkey. Third, the raw spike tracings during recordings of Monkey W were reviewed to ensure that no times of high activity (corresponding to movement) were missed. Since there were not additional times flagged, this step was bypassed in Monkey $\mathrm{N}$.

\section{Data analysis-spike time dynamics}

To compare the spiking rate before and during $\mathrm{N}_{2} \mathrm{O}$ administration, the neural data for Monkey $\mathrm{N}$ were combined for both days (but the neural data of each monkey were kept separate). The pre- $\mathrm{N}_{2} \mathrm{O}$ data included the $15 \mathrm{~min}$ period before $\mathrm{N}_{2} \mathrm{O}$ administration, as this corresponded to the times the monkey was secured in the testing chair without significant motor movements. Pre- $\mathrm{N}_{2} \mathrm{O}$ multiunits with a spiking rate $>2 \mathrm{~Hz}$ were included, and the spikes in the remaining channels were sorted. The pre- $\mathrm{N}_{2} \mathrm{O}$ spiking rate was then determined by averaging across all sorted multiunits. To include only spontaneous activity, only sorted units with firing rate $>0.5 \mathrm{~Hz}$ were analyzed. To compute the spiking rate during $\mathrm{N}_{2} \mathrm{O}$, we averaged the multiunits during the first 45 min of $\mathrm{N}_{2} \mathrm{O}$ (using the same multiunits used in the pre- $\mathrm{N}_{2} \mathrm{O}$ time period). A period of 45 min was chosen to keep the time under $\mathrm{N}_{2} \mathrm{O}$ the same for each day when computing the spiking rate.

Since times of observed monkey movements were not recorded when finger brushings were not being performed, an automated algorithm was used to flag dense neural activity that likely corresponded to monkey movement. When the number of recorded spikes within a $3 \mathrm{~ms}$ time bin exceeded a prespecified threshold, the surrounding $1 \mathrm{~s}$ interval was excluded from the spike rate calculation. This threshold was empirically determined by reviewing raster plots by visual inspection to ensure that these periods of dense neural activity were excluded. The distribution of sorted multiunits was plotted as a two-dimensional histogram of firing rate change during $\mathrm{N}_{2} \mathrm{O}$ and pre- $\mathrm{N}_{2} \mathrm{O}$ firing rates. To compute the trends in spiking rate versus time, the spiking rate was calculated as a running average over $5 \mathrm{~min}$. 


\section{Spectral analysis}

Spectrograms were generated from the broadband signal, sampled at $30 \mathrm{kHz}$, from the Cerebus neural signal processor using MATLAB (version 2017a, MathWorks). Because removing data from the time series introduces discontinuities in the spectrogram, no time series data were removed (e.g., periods with movement are included in the spectrogram). The signal was first decimated using decimate.m, which included a 1000-order FIR (finite impulse response) low-pass filter. After decimation, the signal was high-pass filtered with a 1000-order FIR filter using fir1.m. The spectrogram for each channel was approximated using the mtspecgramc.m function in the Chronux toolbox (version 2.12 v03, Chronux), which uses Thomson's multitaper method, with a time-bandwidth product of 120, a time window of $30 \mathrm{~s}, 239$ tapers, and time step of $15 \mathrm{~s}$. The spectrogram was then averaged across all channels with a spiking rate $>2 \mathrm{~Hz}$, as given in the preceding section. The amplitude was normalized such that the maximum amplitude was at $0 \mathrm{~dB}$.

After observing changes in the spectrogram during $\mathrm{N}_{2} \mathrm{O}$ administration, a period of maximal effect between 10 and 20 min after beginning $\mathrm{N}_{2} \mathrm{O}$ was compared with the period $5-15 \mathrm{~min}$ before $\mathrm{N}_{2} \mathrm{O}$. The spectra were again calculated using Thomson's multitaper method for each channel using the mtspectrumc.m algorithm from the Chronux toolbox using a time-bandwidth product of 120 , $30 \mathrm{~s}$ windows, and 239 tapers. The data were then averaged across all non-noise channels with a spiking rate $>2 \mathrm{~Hz}$ in each respective time session. For display clarity, the spectrum for each monkey was normalized by calculating the magnitude at $10 \mathrm{~Hz}$ in the pre- $\mathrm{N}_{2} \mathrm{O}$ time period and dividing the entire spectrum in the pre- $\mathrm{N}_{2} \mathrm{O}$ and $\mathrm{N}_{2} \mathrm{O}$ periods by this value.

\section{Finger classification}

Finger brushings were performed while $\mathrm{N}_{2} \mathrm{O}$ was administered, and a detailed analysis was performed on 2 experimental days, one for Monkey $\mathrm{W}$ and one for Monkey N (right-sided implant). In both monkeys, fingerbrushing sessions were conducted for $10 \mathrm{~min}$, with 510 min breaks between sessions. In the first few minutes after beginning inhaled $\mathrm{N}_{2} \mathrm{O}$, Monkey $\mathrm{N}$ often reacted with movement, which required many of these finger-brushing trials to be excluded. Although Monkey W did not have this issue, we excluded the initial finger-brushing session in both animals after beginning inhaled $\mathrm{N}_{2} \mathrm{O}$ to be consistent across both animals.

The remaining three brushing sessions for each monkey were labeled as the pre- $\mathrm{N}_{2} \mathrm{O}$, early, and late sessions. In Monkey W, the early session began 23 min after starting $\mathrm{N}_{2} \mathrm{O}$, and the late session began at $45 \mathrm{~min}$. In Monkey $\mathrm{N}$, the early session began 22 min after $\mathrm{N}_{2} \mathrm{O}$, and the late session began at $38 \mathrm{~min}$. Differences in timing in each session were attributed to $\sim 10$ min breaks between sessions for Monkey $\mathrm{W}$ and $\sim 5$ min breaks between sessions for Monkey N.

A naive Bayes classifier with leave-one-out cross-validation was used to classify three or four distinct finger brushings, as previously described (Schroeder et al.,
2016), using unsorted multiunits. Again, unsorted multiunits (as opposed to sorted multiunits) were used to retain information in the neural hash unit. The multiunits used to classify finger brushings all had spiking rates $>2 \mathrm{~Hz}$. Units were not prescreened with ANOVA to include units with potentially small amounts of information.

On both days, four fingers were brushed and the results of classifying all fingers were included in the following analyses. Three fingers for which the effect could be clearly illustrated were selected for visualization. In both monkeys, fingers 2, 3 , and 5 were selected as this combination of fingers in both monkeys had high numbers of modulated units. Because testing periods required motionless and cooperative behavior from the monkey, no attempt was made to use the exact number of trials each day.

In a preliminary analysis using a naive Bayes classifier, sensory content in $\mathrm{S} 1$ appeared to be largely preserved with $\mathrm{N}_{2} \mathrm{O}$ during the finger-brushing session with Monkey N, similar to that found in the study by Schroeder et al. (2016). Further analysis of sensory afferents to M1 is warranted.

\section{Tuning curves and normalized modulation depth}

The modulation depth for each brushing session was calculated. The modulation depth between digits $i$ and $j$ is given below in Equation 1, where $\mu_{i}$ denotes the mean firing rate when digit $i$ is brushed and $\sigma_{i}$ denotes the SD. The $j$ th digit is the finger that minimizes $\mathrm{MD}_{i}$ in Equation 1 , since the $i$ th digit needs to be differentiated from the three other brushed fingers. The total modulation depth for the channel (MD) was defined herein as the average $M D_{i}$ for all four fingers as shown in Equation 2. The normalized $\mathrm{MD}\left(M D_{N}\right)$ is given in Equation 3, where $M D_{\text {rand }}$ is the calculated modulation depth when the fingers associated with the brushing trials are randomly permutated and averaged over 1000 trials. Normalization was necessary because the spiking rates differed across finger-brushing trials and because a finger-brushing session with fewer trials would be biased toward higher modulation depths (for the same reason that the SEM decreases with an increasing number of samples), as follows:

$$
\begin{gathered}
\mathrm{MD}_{i, j}=\frac{\left|\mu_{i}-\mu_{j}\right|}{\sqrt{\sigma_{i}^{2}+\sigma_{j}^{2}}}, \\
\mathrm{MD}=\frac{1}{n} \sum_{i=1}^{4} \mathrm{MD}_{i}, \\
\mathrm{MD}_{N}=\frac{\mathrm{MD}_{i, j}}{\mathrm{MD}_{\text {rand }}},
\end{gathered}
$$

Tuning curves were calculated for all discriminated single units (scores of 3 or 4). The mean and SEM for the spiking rate versus finger brushed are calculated for each of these multiunits.

\section{Experimental design and statistical analysis}

The experimental design, including animal descriptions, is detailed in the preceding sections. Statistical analyses 
were performed on a desktop computer using MATLAB. Unless otherwise described, statistical significance was deemed as $\alpha<0.05$. A one-tailed binomial test was used to evaluate whether finger classification sessions during $\mathrm{N}_{2} \mathrm{O}$ administration performed at a better than chance rate. The chance rates were one in three when brushing three equally likely fingers and one in four when brushing four equally likely fingers. The calculation was made using binocdf. $m$ in MATLAB. When two finger combinations were examined for statistical significance (see Population analysis below), a Bonferroni correction was applied to lower the level for statistical significance to 0.025 . Otherwise, the level of statistical significance was $\alpha=0.05$. Fisher's exact test was used to compare categorical random variables. Parameterized statistical tests between two groups were made with a one-sample, two-tailed $t$ test.

The correlation between $\mathrm{MD}_{N}$ and the $\mathrm{N}_{2} \mathrm{O}$-induced change in firing rate was evaluated for multiunits during the early and late finger-brushing sessions. The change in firing rate was calculated by subtracting the pre- $\mathrm{N}_{2} \mathrm{O}$ firing rate from the firing rate of either the early or late session. The difference was normalized by the pre- $\mathrm{N}_{2} \mathrm{O}$ firing rate to prevent units with high firing rate from dominating the correlation. The MATLAB function fittm. $m$ was to evaluate the correlation.

\section{Results}

\section{Increased spiking rate with administration of $\mathrm{N}_{2} \mathrm{O}$}

In motor cortex, the spiking rate increased after exposure to $\mathrm{N}_{2} \mathrm{O}$. After excluding all channels with a spiking rate of $<2 \mathrm{~Hz}$ and then spike sorting, Monkey W had 72 sorted multiunits, the left implant of Monkey $\mathrm{N}$ had 19 sorted multiunits, and the right implant of Monkey $\mathrm{N}$ had 24 sorted multiunits. The raw tracings from channel 25 in Monkey $\mathrm{W}$ in Figure $1 B$ illustrate the increased spiking rate of a discriminated single unit 15 min into $\mathrm{N}_{2} \mathrm{O}$ administration compared with before $\mathrm{N}_{2} \mathrm{O}$ administration. Included with the raw tracings are the corresponding single-unit waveform and histograms of the interspike intervals before and after $\mathrm{N}_{2} \mathrm{O}$ administration. The raster plots in Figure $1 \mathrm{C}$ also illustrate the typical increased spiking rate of the total population after 15 min of $\mathrm{N}_{2} \mathrm{O}$ administration.

Previous studies suggest that the maximal effect of $\mathrm{N}_{2} \mathrm{O}$ occurs within $15-20$ min of onset (Stevens et al., 1983; Schröter et al., 2012), and Figure $1 D$ shows that the change in baseline spiking rate in motor cortex follows this previously reported trend. There is a rapid increase in spiking rate within the first 15-20 min of $\mathrm{N}_{2} \mathrm{O}$ administration. In all cases, the firing rate either peaks or plateaus at $\sim 20-30 \mathrm{~min}$. The pre- $\mathrm{N}_{2} \mathrm{O}$ baseline firing rate was $8.1 \mathrm{~Hz}$ for Monkey $\mathrm{W}, 4.7 \mathrm{~Hz}$ for the left cortex of Monkey $\mathrm{N}$, and $6.4 \mathrm{~Hz}$ for the right cortex of Monkey $\mathrm{N}$. The average sorted multiunit spiking rate was increased from $8.1 \pm 0.99$ to $10.6 \pm 1.3 \mathrm{~Hz}$ in Monkey $\mathrm{W}(p<0.001$; two-tailed $t$ test) and increased from $5.6 \pm 0.87$ to $7.0 \pm 1.1 \mathrm{~Hz}$ in Monkey N ( $p=0.003$; two-tailed $t$ test). The change in firing rate is shown in Figure $1 E$.

Although firing rate generally increased, with a spiking rate increase in $80 \%$ of the units analyzed, the effect was not uniform. Figure $1 F$ shows a two-dimensional histogram of the change in the firing rate of a multiunit and the pre- $\mathrm{N}_{2} \mathrm{O}$ baseline firing rate of a multiunit. As can be seen in Figure $1 F$, the histogram is centered right of zero, indicating that, as a group, multiunits showed increased firing rate. In some multiunits, there was a substantial increase in firing rate $(>10 \mathrm{~Hz})$, while the majority of multiunits increased by only a few hertz. Of note, the firing rate decreased in only 11 multiunits (15\%) in Monkey W and 12 multiunits (28\%) in Monkey $\mathrm{N}$ with $\mathrm{N}_{2} \mathrm{O}$. There were no observed differences in the waveform morphology in isolated units with increased versus decreased firing rate.

\section{$\mathrm{N}_{2} \mathrm{O}$ modulation of beta- and gamma-band frequencies}

In both monkeys, $\mathrm{N}_{2} \mathrm{O}$ administration increased spectral power at frequencies within $20-45 \mathrm{~Hz}$ that included both beta band $(15-30 \mathrm{~Hz})$ and low gamma band $(30-$ $70 \mathrm{~Hz}$ ). Spectrograms for Monkey W and Monkey N (right implant) are shown in Figure 2, $A$ and $B$, respectively, to illustrate the time evolution of spectral changes with $\mathrm{N}_{2} \mathrm{O}$. Power in the beta and low-gamma band increases beginning at $\sim 5-10 \mathrm{~min}$ in both animals. To highlight the spectral changes under $\mathrm{N}_{2} \mathrm{O}$, spectrograms normalized based on pre- $\mathrm{N}_{2} \mathrm{O}$ values are shown in the bottom panels of Figure 2, $A$ and $B$. Figure 2, $C$ and $D$, depicts, respectively, the power spectra for Monkey $\mathrm{W}$ and the right implant of Monkey $\mathrm{N}$ chosen at the time of maximal effect from the spectrogram, 10-20 min after beginning administration. The comparison of the power spectra before and during $\mathrm{N}_{2} \mathrm{O}$ administration also highlights the increase in spectral power between 20 and $45 \mathrm{~Hz}$. Although times with movement are not excluded from the spectrogram and spectrum, the results are consistent with the results of the power spectra when instances of motor movement are excluded.

\section{$\mathrm{N}_{2} \mathrm{O}$ degrades but does not eliminate classification of finger brushings}

Population analysis

To evaluate information processing associated with spiking and spectral changes, we evaluated the ability to decode sensory information in motor cortex, which is known to represent somatosensory information transferred from S1 (Schroeder et al., 2016). Finger brushings were classified using M1 neurons (Fig. 3A). As shown in Figure $3 B$, these somatosensory stimuli were classified at the following three times: pre- $\mathrm{N}_{2} \mathrm{O}$ (purple), early during $\mathrm{N}_{2} \mathrm{O}$ (blue), and late (red). To prevent introduction of bias, classification was performed on all unsorted multiunits with a firing rate of $>2 \mathrm{~Hz}$ in all finger-brushing sessions. This selection process left 53 units in Monkey $W$ and 19 units in Monkey N. Across trials in Monkey W, there were statistically significant differences in spiking rate, as follows: pre- $\mathrm{N}_{2} \mathrm{O}$, at $13.41 \pm 0.27 \mathrm{~Hz}$, and $\mathrm{N}_{2} \mathrm{O}$ at $19.20 \pm$ 0.27 ( $p<0.001 ; t$ test). Across all trials in Monkey $\mathrm{N}$, there were also statistically significant differences: pre- $\mathrm{N}_{2} \mathrm{O}$ at $8.82 \pm 0.19 \mathrm{~Hz}$, and $\mathrm{N}_{2} \mathrm{O}$ at $11.35 \pm 0.19$ ( $p<0.001 ; t$ test). 
A

\section{Monkey W}
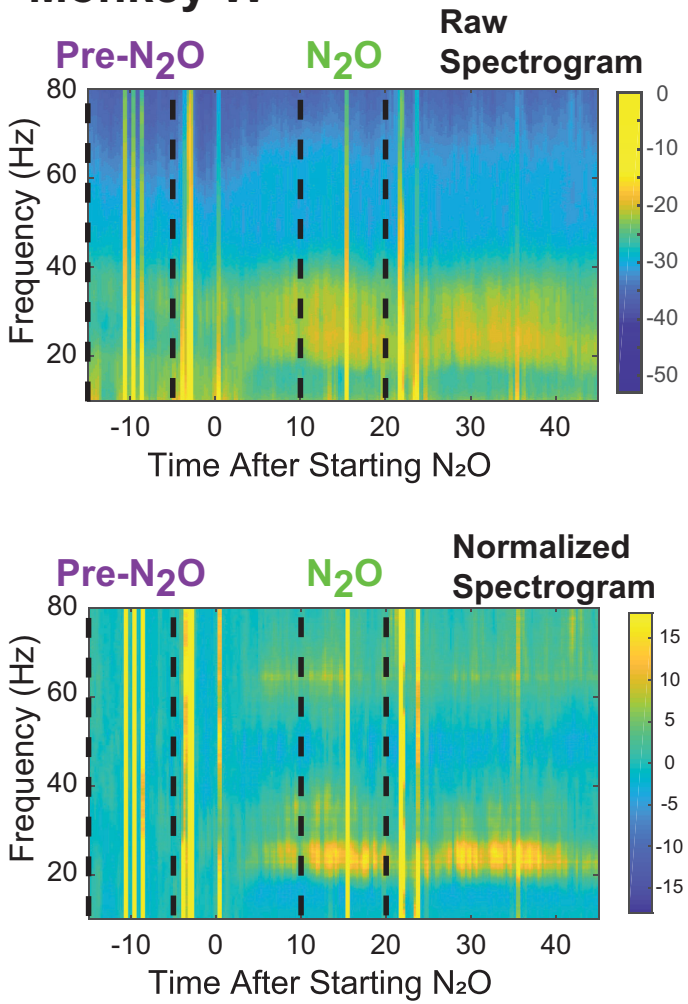

C

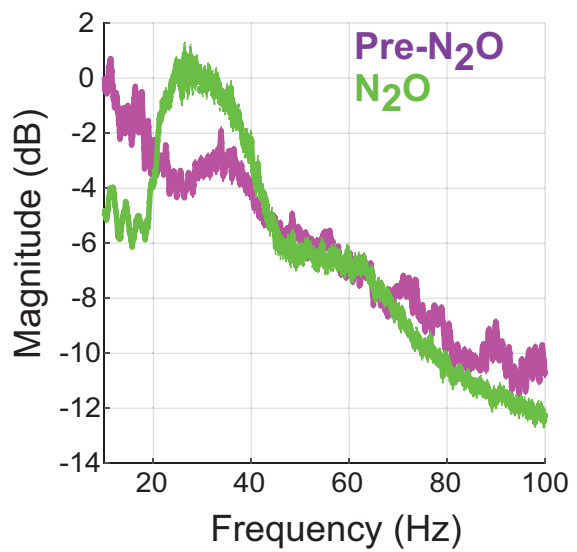

B

\section{Monkey $\mathbf{N}$}
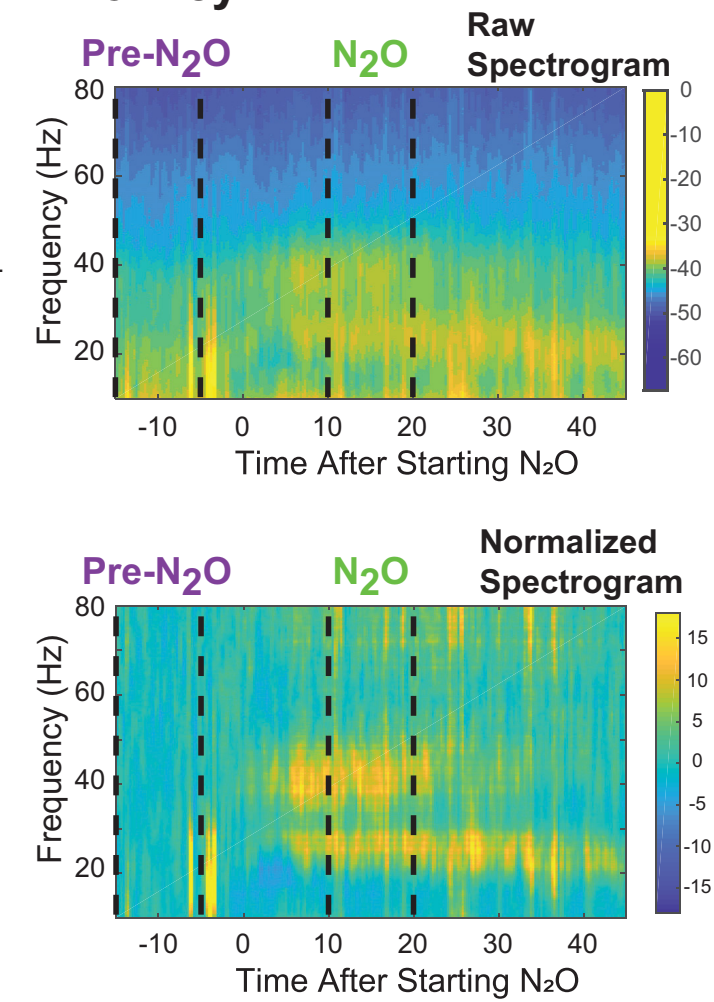

D

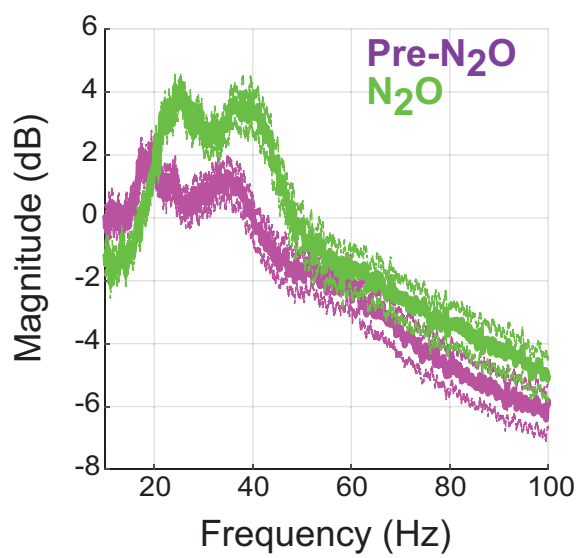

Figure 2. Increased high-frequency power during nitrous oxide. A, B, Averaged spectrograms for 55 channels in Monkey W $(\boldsymbol{A})$ and for 21 channels of the right cortex implant in Monkey $N(B)$. The raw spectrograms for each monkey are presented in the top panels of $\boldsymbol{A}$ and $\boldsymbol{B}$. The bottom panels depict spectrograms normalized by the average spectral content in the pre- $\mathrm{N}_{2} \mathrm{O}$ period. The vertical lines represent an artifact. $\boldsymbol{C}, \boldsymbol{D}$, The corresponding averaged power spectrum from 15 to 5 min before $\mathrm{N}_{2} \mathrm{O}$ (purple) and 10-20 min into $\mathrm{N}_{2} \mathrm{O}$ administration for Monkey W $(\boldsymbol{C})$ and Monkey $N(\boldsymbol{D})$. SEM is displayed with dashed lines. To remove the effects of pink noise, the power spectra in $\boldsymbol{C}$ and $\boldsymbol{D}$ are normalized by $1 / f$.

In both monkeys and before $\mathrm{N}_{2} \mathrm{O}$, brushings of four fingers could be classified better than chance (chance level at 0.25$)$. In Monkey W, the proportion of correct classification was $0.50 \pm 0.11(p=0.014$; binomial test, 20 trials). In Monkey $\mathrm{N}$, brushings of four fingers were correctly classified at $0.43 \pm 0.067(p=0.003 ; 56$ trials).
To increase the effect for visualization, the confusion plots shown in Figure $3 \mathrm{C}$ illustrate the distribution of correct classification using the same three fingers, D2, D3, and D5. For fingers D2, D3, and D5, there were 13 modulated units in Monkey W and 8 in Monkey N (screened with ANOVA test using $\alpha=0.05$ ). 
A

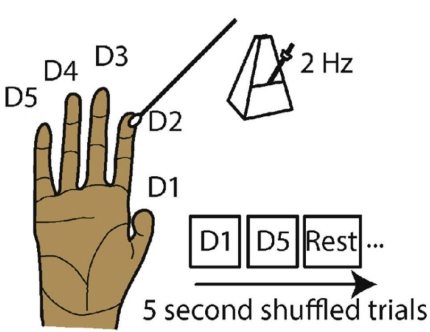

B

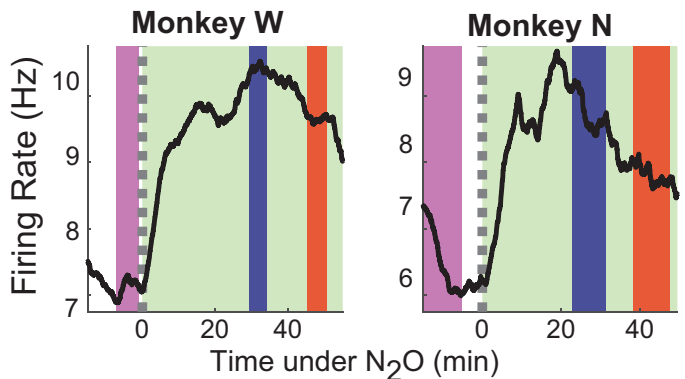

C

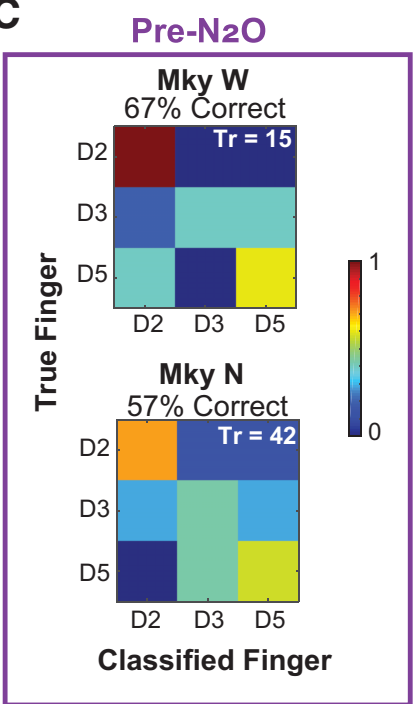

$\mathbf{F}$

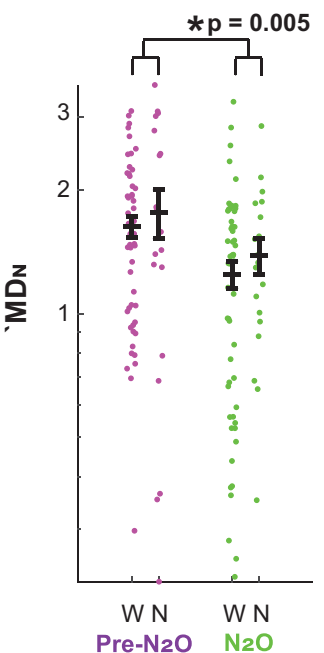

D

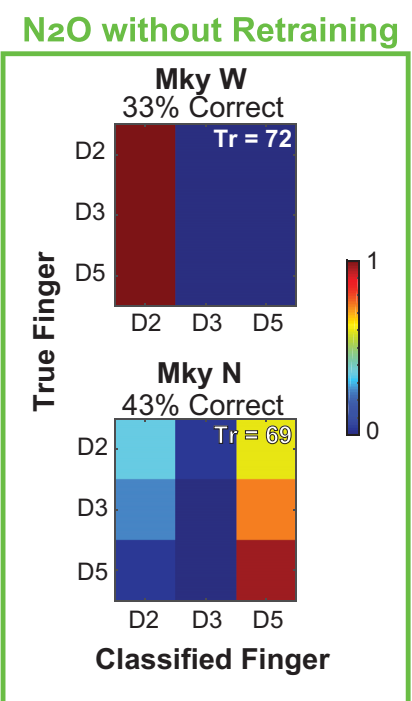

E

$\mathrm{N}_{2} \mathrm{O}$ with Retraining

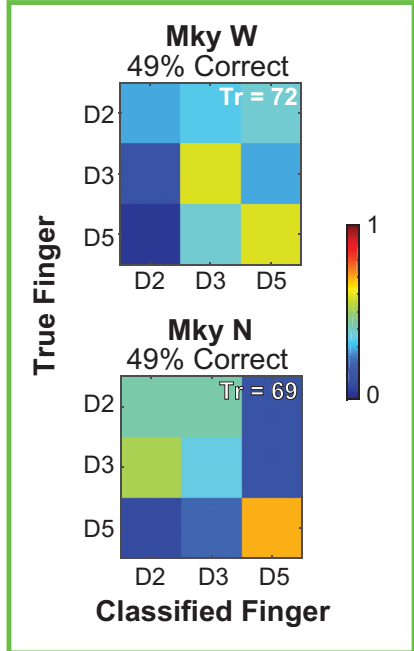

G

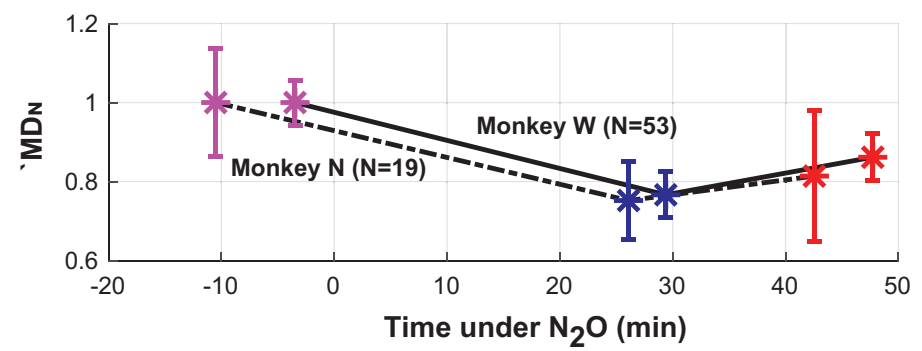

Figure 3. Transient degradation of somatosensory information in motor cortex. $\boldsymbol{A}$, The experimental setup consisted of random stimulation of individual fingers at $2 \mathrm{~Hz}$ strokes in trials of $5 \mathrm{~s}$ duration. $\boldsymbol{B}$. Trends of sorted multiunit firing rate for each monkey. The shaded regions highlight the times when fingers were decoded to compare performance in pre- $\mathrm{N}_{2} \mathrm{O}$ state (purple) and early (blue) and late (red) $\mathrm{N}_{2} \mathrm{O}$ administration. $\boldsymbol{C}$, Confusion plots for each monkey illustrate performance of the Naive Bayes classifier when classifying finger brushings in the pre- $\mathrm{N}_{2} \mathrm{O}$ state. The vertical axis is the true finger brushed while the horizontal axis is the decoded finger. The percentage correct is given above each respective plot. Tr, Number of trials classified. The insert to the right of the confusion plots is the legend. $\boldsymbol{D}$, Confusion plot during $\mathrm{N}_{2} \mathrm{O}$ (combined early and late brushing sessions) when the classifier is trained using data from the pre- $\mathrm{N}_{2} \mathrm{O}$ finger-brushing session. $\boldsymbol{E}$, Confusion plot during $\mathrm{N}_{2} \mathrm{O}$ (combined early and late sessions) when training the classifier on the current session (early and late) using leave-one-out cross-validation. $\boldsymbol{F}$. The $\mathrm{MD}_{N}$ for all multiunits in the pre$\mathrm{N}_{2} \mathrm{O}$ (purple) and $\mathrm{N}_{2} \mathrm{O}$ (green) brushing sessions. The $\mathrm{MD}_{N}$ of multiunits during $\mathrm{N}_{2} \mathrm{O}$ sessions was averaged for both the early and late sessions. W denotes Monkey W, and N denotes Monkey N. Each filled circle represents one multiunit. The horizontal bar (in black) and error bars represent the mean and SEM. The asterisk (*) denotes statistical significance. The $y$-axis is in log scale to 
continued

better visualize the data. G, The mean modulation depths for the pre- $\mathrm{N}_{2} \mathrm{O}$ (purple), early $\mathrm{N}_{2} \mathrm{O}$ (blue), and late $\mathrm{N}_{2} \mathrm{O}$ (red) finger-brushing sessions. The asterisks and error bars indicate the mean and SEM. The solid line denotes Monkey W, and the dashed line denotes Monkey N. Panel $\boldsymbol{A}$ is adapted and reprinted with permission from Schroeder et al. (2016).

To determine whether $\mathrm{N}_{2} \mathrm{O}$ impacted the encoding of somatosensory information in M1, the Naive Bayes classifier trained in the pre- $\mathrm{N}_{2} \mathrm{O}$ session was used to classify finger brushings during $\mathrm{N}_{2} \mathrm{O}$ administration. For the illustrative fingers (D2, D3, D5), the proportion of correct finger classifications when combining early and late drops were $0.33 \pm 0.06(p=0.54)$ in Monkey $W$ and $0.43 \pm 0.06$ in Monkey $\mathrm{N}(p=0.05)$, as illustrated in Figure $3 D$. However, the correct classification improves when the Naive Bayes classifier is trained using trials from the current brushing session under $\mathrm{N}_{2} \mathrm{O}$ (using leave-one-out cross-validation). For fingers D2, D3, and D5, the percentage correct improved to $0.49 \pm 0.06 \%$ for both Monkey W $(p=0.005)$ and Monkey N $(p=0.004)$, and the confusion matrices are shown in Figure $3 E$. For reference, the correct classification using four fingers was $0.38 \pm 0.05$ for Monkey W $(p=0.005)$ and $0.30 \pm 0.05$ for Monkey $N(p=0.10)$. Combining trials between both monkeys, there was a statistically significant drop in the correct finger classifications from $0.50 \pm 0.06$ before $\mathrm{N}_{2} \mathrm{O}$ to $0.34 \pm 0.03$ during $\mathrm{N}_{2} \mathrm{O}(p=0.018)$. Thus, $\mathrm{N}_{2} \mathrm{O}$ administration degrades but does not eliminate the representation of somatosensory content in M1.

\section{Multiunit modulation depth analysis}

Although the encoding of somatosensory information is clearly affected by $\mathrm{N}_{2} \mathrm{O}$, the effect on individual multiunits requires separate analysis. The $M D_{N}$ of all multiunits is shown in Figure $3 F$, where $\mathrm{MD}_{N}<1$ corresponds to no modulation. In both monkeys, the mean $\mathrm{MD}_{N}$ is greater before than during $\mathrm{N}_{2} \mathrm{O}$ administration $(p=0.005)$. $\mathrm{MD}_{N}$ decreases from $1.63 \pm 0.09$ to $1.40 \pm 0.10$ in Monkey W and from $1.76 \pm 0.24$ to $1.38 \pm 0.17$ in Monkey N. Despite this drop, combining the number of modulated channels $\left(M D_{N}>2\right)$ across both channels revealed an average of 11 modulated units per $\mathrm{N}_{2} \mathrm{O}$ brushing session. However, this is less than the 22 modulated units across both monkeys during the pre- $\mathrm{N}_{2} \mathrm{O}$ brushing session $(p=0.046)$. When the well modulated units $\left(\mathrm{MD}_{N}>2\right)$ are removed, the classification of D2, D3, and D5 during $\mathrm{N}_{2} \mathrm{O}$ (Fig. 3E) drops to $0.43 \pm 0.06$ in Monkey $W(p=0.054)$ and to $0.26 \pm 0.05$ in Monkey N ( $p=0.92)$, and neither was statistically better than chance.

During $\mathrm{N}_{2} \mathrm{O}$ administration, there was no correlation between the modulation depth and the change in firing rate during $\mathrm{N}_{2} \mathrm{O}\left(R^{2}<0.001, p=0.93\right)$, meaning that units with large increases in firing rate were not more likely to have a low $\mathrm{MD}_{N}$. As will be illustrated with discriminated single units in the next section, some units lost modulation despite no change in spiking rate, and some units maintained modulation despite increased firing rate.

When the early and late $\mathrm{N}_{2} \mathrm{O}$ finger-brushing sessions are separated (Fig. $3 G$ ), $\mathrm{MD}_{N}$ does not continue to decrease with continued $\mathrm{N}_{2} \mathrm{O}$ administration, despite continued administration of $\mathrm{N}_{2} \mathrm{O}$. The modulation depth, in fact, increases, although the increase is not statistically significant $(p=0.28)$.

\section{Discriminated single-unit examples}

To better understand how individual neurons representing somatosensory information are affected by $\mathrm{N}_{2} \mathrm{O}$, we examined the tuning curves of the discriminated single units for each monkey by comparing the pre- $\mathrm{N}_{2} \mathrm{O}$ with the early and late epochs. Combining both monkeys, 19 discriminated units were modulated in at least one fingerbrushing session (ANOVA with $\alpha<0.05$ ). Four illustrative examples of the tuning curves for modulated single units are given in Figure $4 A$. The curves illustrate the mean firing rate when one of the three fingers (D2, D3, or D5) was brushed. As mentioned above, despite the increased firing rate, these units retained their tuning for finger brushings. In the raw voltage tracings in Figure $4 B$, the example for channel 5 in Monkey $\mathrm{N}$ illustrates how brushing D5 continues to evoke a higher firing rate than D3 despite an increased baseline firing rate. Additionally, there were examples where fingers not tuned in the pre- $\mathrm{N}_{2} \mathrm{O}$ brushing session became tuned to finger brushings, as in channel 89 in Monkey W.

As described in the preceding section, tuning is lost in many single units during $\mathrm{N}_{2} \mathrm{O}$ administration (Fig. $4 C$ ). This loss in tuning occurred both in units with increased firing rate (channel 82 , Monkey $\mathrm{N}$ ) and in units with similar firing rates as the pre- $\mathrm{N}_{2} \mathrm{O}$ brushing session (channel 96, Monkey W). Raw tracings of channel 82 in Monkey N illustrate how single-unit activity does not clearly differentiate the brushings of fingers D3 and D5 during $\mathrm{N}_{2} \mathrm{O}$, although differentiable in the pre- $\mathrm{N}_{2} \mathrm{O}$ session. Thus, regardless of changes in firing rate, many units were no longer modulated during $\mathrm{N}_{2} \mathrm{O}$. The remaining 11 modulated units are given in Figure 5.

\section{Discussion}

We have demonstrated that, with continuous inhalation of $\mathrm{N}_{2} \mathrm{O}$, (1) the spiking rate of motor cortex neurons increases, (2) high-frequency power (in beta and low gamma bands) increases, and (3) measurable somatosensory information represented in the motor cortex persists but is degraded while a smaller number of persistently tuned units remain. The change in somatosensory encoding in M1 is explained by a loss of modulated multiunits and a general decrease in modulation across the population. However, there does not appear to be a strong relationship between the increase in single-unit activity and its modulation depth under $\mathrm{N}_{2} \mathrm{O}$, suggesting a possible dissociation of representation and changes in firing rate.

\section{Time-frequency dynamics}

A paucity of data exists concerning the effects of NMDA receptor antagonists, like $\mathrm{N}_{2} \mathrm{O}$, on mesoscopic neural 
A

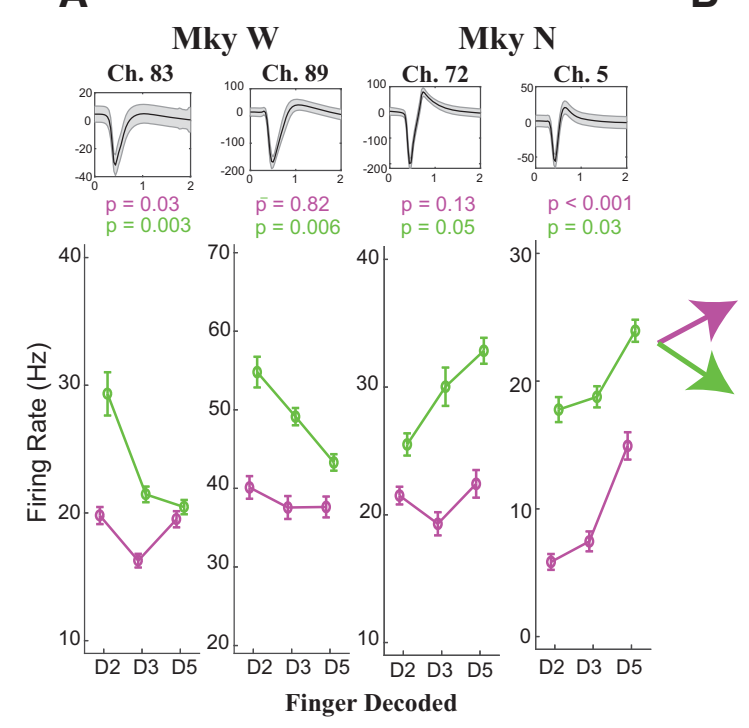

B
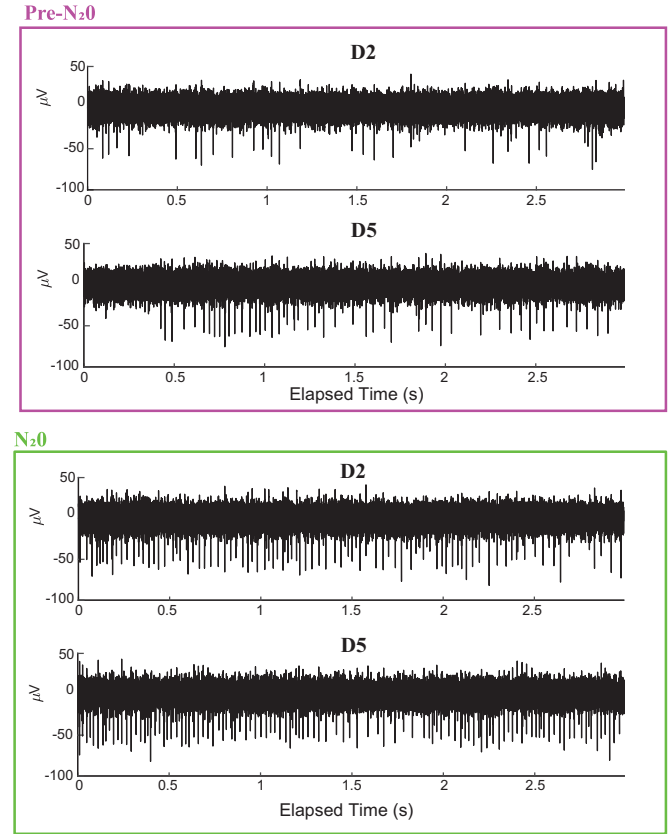

C

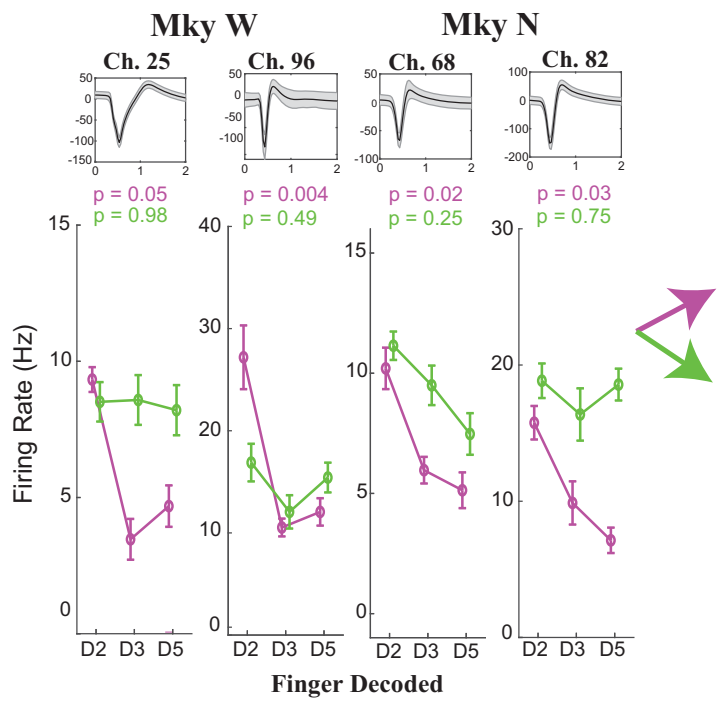

D
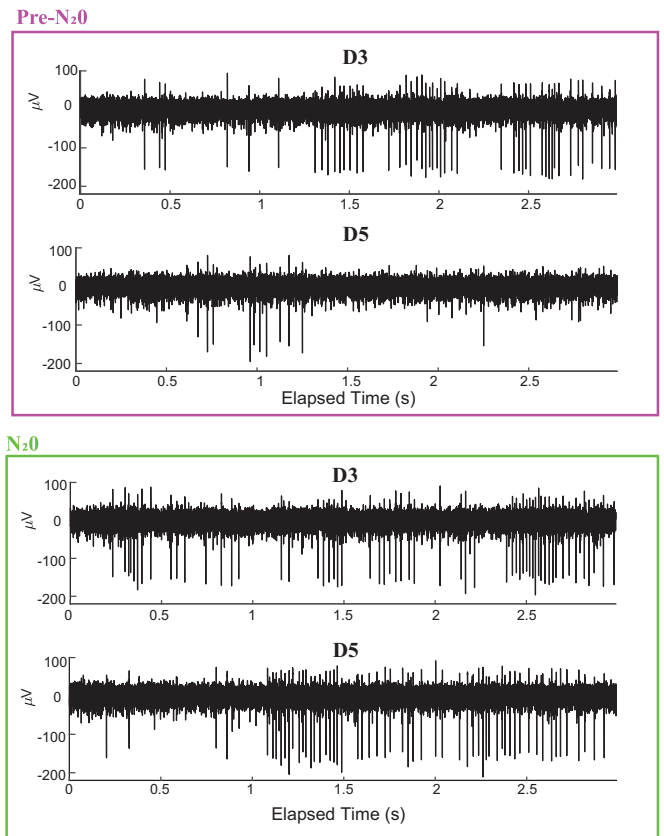

Figure 4. Discriminated single-unit tuning curves. $\boldsymbol{A}$, Tuning curves for four modulated (ANOVA, with $\alpha<0.1$ ), discriminated single units during $\mathrm{N}_{2} \mathrm{O}$ administration. Single units are presented on the left for Monkey W and on the right for Monkey N. Each single unit is labeled with the channel on the array, the average waveform tracing (black line, mean; shaded gray, SD), and the tuning curve. The tuning curve depicts the mean firing rate of the single unit as a function of the finger brushed both in the pre- $\mathrm{N}_{2} \mathrm{O}$ period (purple) and during $\mathrm{N}_{2} \mathrm{O}$ (green). The error bars denote the SEM. The $p$ values calculated with one-way ANOVA are given for both the pre- $\mathrm{N}_{2} \mathrm{O}$ and $\mathrm{N}_{2} \mathrm{O}$ tuning curves. $\boldsymbol{B}$, Raw voltage tracings for the modulated discriminated single unit in channel 5 for Monkey $\mathrm{N}$ in the pre- $\mathrm{N}_{2} \mathrm{O}$ (purple) and $\mathrm{N}_{2} \mathrm{O}$ (green) periods. In each pane, the top tracing resulted when the second digit (D2) was brushed and the bottom plot resulted when the fifth digit (D5) was brushed. The elapsed time is relative to 10 min before beginning $\mathrm{N}_{2} \mathrm{O}$. C , Four discriminated single units that were originally modulated (ANOVA, with $\alpha<0.1$ ) in the pre- $\mathrm{N}_{2} \mathrm{O}$ period but lost modulation during $\mathrm{N}_{2} \mathrm{O}$ administration. $\boldsymbol{D}$, Raw voltage tracings illustrating a typical finger-brushing trial for channel 82 in Monkey N. The elapsed time is relative to 15 min after beginning $\mathrm{N}_{2} \mathrm{O}$.

networks. Recently, canonical agents that potentiate GABA, such as propofol and isoflurane, have been shown to decrease spiking rate in cortical mesoscopic networks (Lewis et al., 2012; Ishizawa et al., 2016; Wenzel et al.,
2019). Wenzel et al. (2019) administered isoflurane at varying concentrations and found a depression of spiking activity in somatosensory and visual cortex that was inversely related to anesthetic depth. Lewis et al. (2012) ad- 
Mky W
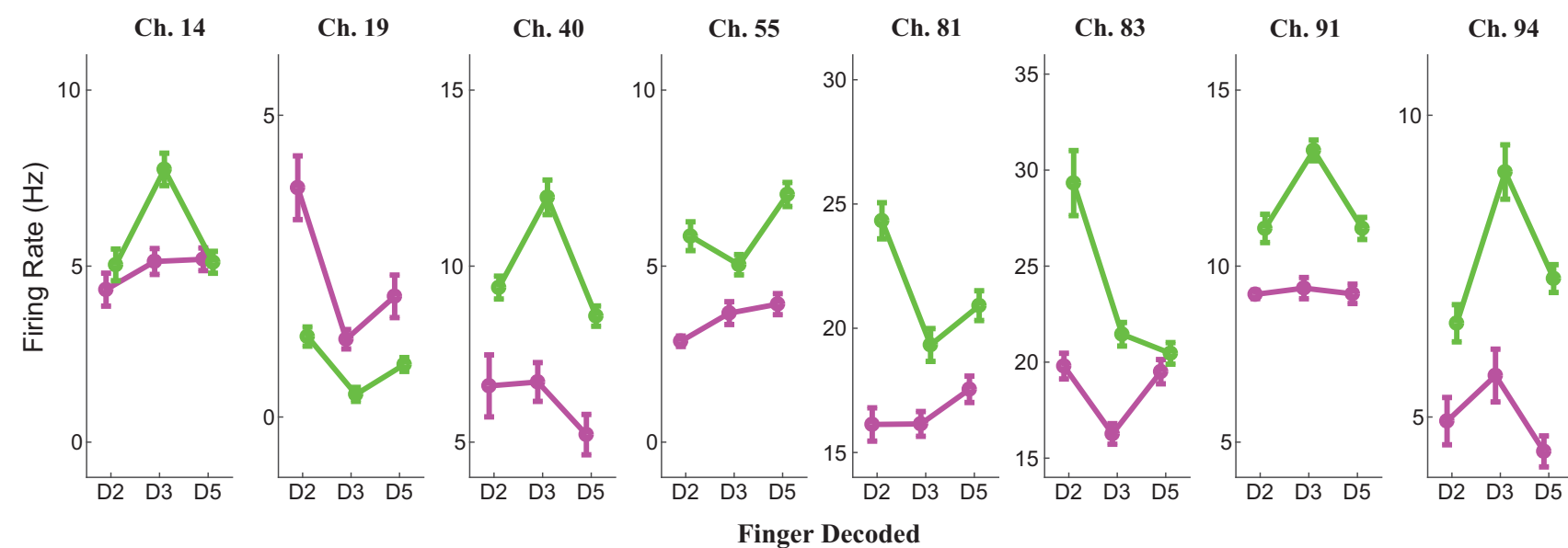

B

Mky N

Ch. 33

Ch. 43

Ch. 85
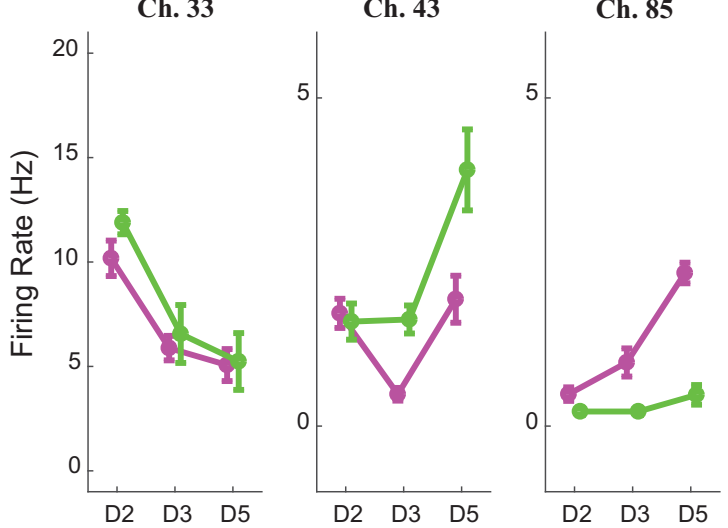

Finger Decoded

Figure 5. Remaining discriminated single-unit tuning curves. $\boldsymbol{A}, \boldsymbol{B}$, Monkey $\mathrm{W}(\boldsymbol{A})$ and Monkey $\mathrm{N}(\boldsymbol{B})$. The tuning curve depicts the mean firing rate of the single unit as a function of the finger brushed both in the pre- $\mathrm{N}_{2} \mathrm{O}$ period (purple) and during $\mathrm{N}_{2} \mathrm{O}(\mathrm{green})$. The error bars denote the SEM.

ministered bolus doses of propofol to induce loss of consciousness and observed decreased spiking activity in temporal lobes. Ishizawa et al. (2016) administered propofol at a continuous rate to induce loss of consciousness and also observed decreased spiking activity in somatosensory and frontal ventral premotor cortices with loss of consciousness. NMDA receptor antagonists are well known to variably modulate neuronal firing rate, depending on neuron type and anatomic location (Patel and Chapin, 1990; Homayoun and Moghaddam, 2007; Wang et al., 2013; Schroeder et al., 2016).

Unlike GABA-potentiating medications, $\mathrm{N}_{2} \mathrm{O}$, an NMDA receptor antagonist, has previously been observed to increase spiking rate in a reticular activating system, but to decrease spiking rate of somatosensory thalamic relay neurons (Kawamoto et al., 1990). In our study, the spiking rate of motor cortex neurons increased with subanesthetic $\mathrm{N}_{2} \mathrm{O}$. The mechanism for the observed increase in spiking rate is likely because of preferential antagonism of NMDA receptors on inhibitory interneurons that disinhibits pyramidal neurons, as previously shown for the NMDA receptor antagonist dizocilpine maleate (MK801; Homayoun and Moghaddam, 2007). In contrast to $\mathrm{N}_{2} \mathrm{O}$ producing increased spiking rates of M1 neurons, previously reported spiking rates of $\mathrm{M} 1$ neurons remained unchanged in nonhuman primates at anesthetic doses of ketamine and an NMDA receptor antagonist (Schroeder et al., 2016). However, at subanesthetic doses of ketamine, Mori et al. (1971) previously showed that multiunit activity increased in the thalamus and reticular activating system of a cat.

Nitrous oxide has spectral properties unlike typical anesthetics potentiating GABA. With microarray recordings, Ishizawa et al. (2016) showed gamma and high beta oscillations lasting a few minutes with propofol-induced loss of consciousness, followed by slow-frequency delta oscillations. In particular, after beginning propofol infusion but 
before loss of consciousness (i.e., subanesthetic doses), spectral plots suggest an increase in high beta $(18-25 \mathrm{~Hz})$ in $\mathrm{S} 1$ and in low gamma $(25-34 \mathrm{~Hz})$ in ventral premotor cortex that is similar to our spectral findings with subanesthetic $\mathrm{N}_{2} \mathrm{O}$. Lewis et al. (2012) likewise found the appearance of slow $(<1 \mathrm{~Hz})$ oscillations in local field potentials after loss of consciousness induced by propofol. In spectral analyses of anesthetic doses of ketamine, Lee et al. (2013) showed a relative increase in gamma band power and a decrease in beta-band power in frontal/parietal EEG data. Schroeder et al. (2016) demonstrated the same trends in LFPs of S1 and less obvious trends in M1. Likewise, Ballesteros et al. (2020) found a gradual increase in high beta, low gamma power in ventral premotor cortex, S1, and secondary somatosensory cortex. Although there are no mesoscopic LFP spectral data with $\mathrm{N}_{2} \mathrm{O}$, previous spectral analyses with EEG data show that $\mathrm{N}_{2} \mathrm{O}$ can increase and decrease high-frequency power (Yamamura et al., 1981; Rampil et al., 1998; Foster and Liley, 2011, 2013; Pelentritou et al., 2019). We found increased high-frequency $(>20-45 \mathrm{~Hz})$ power in motor cortex within beta and gamma bands. Within the beta band, the increase was seen primarily in high beta activity $(\sim 25 \mathrm{~Hz})$ as opposed to the low beta band $(\sim 15 \mathrm{~Hz})$. While both high and low beta bands are thought to originate in cortical layer 5 , the high beta band is thought to be associated with sensory stimuli leading to sustained movement, while the low beta band is associated with coordination of cell assemblies in the absence of sensory stimuli and may be important for processes such as working memory (Roopun et al., 2006; Kopell et al., 2011; Gelastopoulos et al., 2019). Within the gamma band, the changes are similar to the increased gamma power described by Yamamura et al. (1981), who reported a peak at $34 \mathrm{~Hz}$ with $70 \% \mathrm{~N}_{2} \mathrm{O}$; and Rampil et al. (1998), who reported dual peaks at $40-50$ and $70-110 \mathrm{~Hz}$ with $50 \% \quad \mathrm{~N}_{2} \mathrm{O}$. The gamma power differences in the literature may be attributed to regional variation or to the lower spatial resolution of EEG leads, as suggested by others (Ray et al., 2008; Eagleman et al., 2018).

\section{$\mathrm{N}_{2} \mathrm{O}$ degrades $\mathrm{M} 1$ somatosensory representation}

Anesthetic agents are diverse in terms of their molecular targets and effect on neuronal activity. Despite these differences, they all share a similar functional property of reversibly suppressing consciousness at anesthetic doses or altering cognition at subanesthetic doses. The mechanism by which GABAergic anesthetics disrupt neural function appears to be clear-they potentiate inhibition and reduce neural activity (Boveroux et al., 2010; Schrouff et al., 2011; Hudetz, 2012). However, it is not clear how non-GABAergic anesthetics affect consciousness or cognition. As discussed above, the NMDA receptor antagonists ketamine and $\mathrm{N}_{2} \mathrm{O}$ increase high-frequency oscillations and neural firing rates. While GABAergic drugs depress information transfer, non-GABAergic drugs like ketamine and $\mathrm{N}_{2} \mathrm{O}$ are thought to disinhibit pyramidal neurons, leading to dysregulated activity that disrupts information processing (Homayoun and Moghaddam, 2007). Our data show that there is decreased somatosensory content that is not simply explained by interference from the increases in firing rate, because firing rate changes were not correlated with modulation depth (i.e., neuronal tuning). Furthermore, examples of single units without changes in firing rate were found to lose tuning to finger brushing, and other single units with increased firing rates were also found to remain tuned to finger brushings. Thus, our data in nonhuman primate cortex do not support the hypothesis of a clear causal link between increased neural firing patterns and disruptions in information transfer/representation. Further studies are needed to clarify the exact influence of $\mathrm{N}_{2} \mathrm{O}$-induced changes in firing rate on somatosensory representation.

\section{Limitations}

One limitation of this study is that only motor cortex was studied. However, motor cortex was chosen to emphasize the effects of corticocortical somatosensory pathways, although other somatosensory pathways exist, including thalamocortical or corticothalamocortical pathways (Petrof et al., 2015; Mo and Sherman, 2019). Great care was taken to avoid skin indentation with finger brushings, and recording periods with motor movements were excluded to reduce the contribution of thalamocortical inputs. Although this data exclusion has the potential to introduce bias, identical methods for excluding movement artifacts were used throughout all finger-brushing sessions. Second, S1-to-M1 transfer was not measured directly. However, the sensory brushings used in this study have been previously validated as a model of S1-to-M1 information transfer using anesthetic doses of another NMDA antagonist, ketamine, where S1 content was largely preserved and M1 content was lost. Although transfer from S1 to M1 was not explicitly studied here, S1 somatosensory preservation was anecdotally confirmed on $1 \mathrm{~d}$ with Monkey $\mathrm{N}$ using a Naive Bayes analysis. Thus, we feel that $\mathrm{M} 1$ somatosensory content is a likely surrogate for transfer from $\mathrm{S} 1$ to $\mathrm{M} 1$. However, the delineation of a more detailed effect of $\mathrm{N}_{2} \mathrm{O}$ on specific somatosensory afferents requires further study. Additionally, a possible confounder to interpreting the drop in accuracy of finger classification would be if an alternate process (e.g., agitation, fear) interfered with somatosensory content. However, preliminary control tests did not show significant differences in the number of finger brushings correctly classified with or without the face mask. Last, $\mathrm{N}_{2} \mathrm{O}$ was not delivered in a closed circuit accompanied by high-fidelity gas monitoring, creating the potential for undetected alterations in $\mathrm{N}_{2} \mathrm{O}$, oxygen, or carbon dioxide. However, a tight mask seal was ensured at the beginning of each experiment, and monkeys remained awake and cooperative with normal breathing rate and respiratory excursions. Thus, a significant confound that would mitigate the interpretation of these results is not likely.

\section{Conclusion}

In this study, we investigated the effects of subanesthetic concentrations of $\mathrm{N}_{2} \mathrm{O}$ on mesoscopic networks in 
primary motor cortex of the nonhuman primate. Both spiking rate and high-frequency spectral content of motor cortex neurons increased in response to $\mathrm{N}_{2} \mathrm{O}$. With ongoing $\mathrm{N}_{2} \mathrm{O}$, measurable somatosensory content and number of modulated units in M1 decreased but were not eliminated. The shift to faster dynamics is not clearly associated with the somatosensory representation on a neuronal level and may suggest additional mechanisms of $\mathrm{N}_{2} \mathrm{O}$ that alter perception.

\section{References}

Akeju O, Song AH, Hamilos AE, Pavone KJ, Flores FJ, Brown EN, Purdon PL (2016) Electroencephalogram signatures of ketamine anesthesia-induced unconsciousness. Clin Neurophysiol 127:2414-2422.

Andersson G (1995) Cortico-cortical mediation of short-latency (lemniscal) sensory input to the motor cortex in deeply pentobarbitone anaesthetized cats. Acta Physiol Scand 153:381-392.

Ballesteros JJ, Huang P, Patel SR, Eskandar EN, Ishizawa Y (2020) Dynamics of ketamine-induced loss and return of consciousness across primate neocortex. Anesthesiology 132:750-762.

Boveroux P, Vanhaudenhuyse A, Bruno MA, Noirhomme Q, Lauwick S, Luxen A, Degueldre C, Plenevaux A, Schnakers C, Phillips C, Brichant JF, Bonhomme V, Maquet P, Greicius MD, Laureys S, Boly M (2010) Breakdown of within- and between-network resting state functional magnetic resonance imaging connectivity during propofol-induced loss of consciousness. Anesthesiology 113:1038-1053.

Cao W, Zhang F, Yu H, Hu B, Meng Q (2018) Preliminary research of a novel center-driven robot for upper extremity rehabilitation. Technol Health Care 26:409-420.

Deutsch G, Samra SK (1990) Effects of nitrous oxide on global and regional cortical blood flow. Stroke 21:1293-1298.

Eagleman SL, Drover CM, Drover DR, Ouellette NT, Maclver MB (2018) Remifentanil and nitrous oxide anesthesia produces a unique pattern of EEG activity during loss and recovery of response. Front Hum Neurosci 12:173.

Farkas T, Kis Z, Toldi J, Wolff J-R (1999) Activation of the primary motor cortex by somatosensory stimulation in adult rats is mediated mainly by associational connections from the somatosensory cortex. Neuroscience 90:353-361.

Foster BL, Liley DT (2011) Nitrous oxide paradoxically modulates slow electroencephalogram oscillations: implications for anesthesia monitoring. Anesth Analg 113:758-765.

Foster BL, Liley DT (2013) Effects of nitrous oxide sedation on resting electroencephalogram topography. Clin Neurophysiol 124:417423.

Gelastopoulos A, Whittington MA, Kopell NJ (2019) Parietal low beta rhythm provides a dynamical substrate for a working memory buffer. Proc Natl Acad Sci U S A 116:16613-16620.

Homayoun H, Moghaddam B (2007) NMDA receptor hypofunction produces opposite effects on prefrontal cortex interneurons and pyramidal neurons. J Neurosci 27:11496-11500.

Huang Z, Liu X, Mashour GA, Hudetz AG (2018) Timescales of intrinsic BOLD signal dynamics and functional connectivity in pharmacologic and neuropathologic states of unconsciousness. J Neurosci 38:2304-2317.

Hudetz AG (2012) General anesthesia and human brain connectivity. Brain Connect 2:291-302.

Icaza EE, Mashour GA (2013) Altered states: psychedelics and anesthetics. Anesthesiology 119:1255-1260.

Ishizawa Y, Ahmed OJ, Patel SR, Gale JT, Sierra-Mercado D, Brown EN, Eskandar EN (2016) Dynamics of propofol-induced loss of consciousness across primate neocortex. J Neurosci 36:77187726 .

Jevtović-Todorović V, Todorović SM, Mennerick S, Powell S, Dikranian K, Benshoff N, Zorumski CF, Olney JW (1998) Nitrous oxide (laughing gas) is an NMDA antagonist, neuroprotectant and neurotoxin. Nat Med 4:460-463.

Kawamoto T, Shingu K, Mori K (1990) Effects of nitrous oxide on the somatosensory evoked response in cats. J Anesth 4:51-60.

Kopell N, Whittington MA, Kramer MA (2011) Neuronal assembly dynamics in the beta1 frequency range permits short-term memory. Proc Natl Acad Sci USA 108:3779-3784.

Lee U, Mashour GA (2018) Role of network science in the study of anesthetic state transitions. Anesthesiology 129:1029-1044.

Lee U, Ku S, Noh G, Baek S, Choi B, Mashour GA (2013) Disruption of frontal-parietal communication by ketamine, propofol, and sevoflurane. Anesthesiology 118:1264-1275.

Lewis LD, Weiner VS, Mukamel EA, Donoghue JA, Eskandar EN, Madsen JR, Anderson WS, Hochberg LR, Cash SS, Brown EN, Purdon PL (2012) Rapid fragmentation of neuronal networks at the onset of propofol-induced unconsciousness. Proc Natl Acad Sci U S A 109:E3377-E3386.

Mao T, Kusefoglu D, Hooks BM, Huber D, Petreanu L, Svoboda K (2011) Long-range neuronal circuits underlying the interaction between sensory and motor cortex. Neuron 72:111-123.

Mo C, Sherman SM (2019) A sensorimotor pathway via higher-order thalamus. J Neurosci 39:692-704.

Mori K, Kawamata M, Mitani H, Yamazaki Y, Fujita M (1971) A neurophysiologic study of ketamine anesthesia in the cat. Anesthesiology 35:373-382.

Pal D, Hambrecht-Wiedbusch VS, Silverstein BH, Mashour GA (2015) Electroencephalographic coherence and cortical acetylcholine during ketamine-induced unconsciousness. $\mathrm{Br} \mathrm{J}$ Anaesth 114:979-989.

Patel IM, Chapin JK (1990) Ketamine effects on somatosensory cortical single neurons and on behavior in rats. Anesth Analg 70:635644.

Pelentritou A, Kuhlmann L, Cormack J, Mcguigan S, Woods W, Muthukumaraswamy S, Liley D (2019) In search of universal cortical power changes linked to NMDA-antagonist based anesthetic induced reductions in consciousness. bioRxiv. Advance online publication. Retrieved March 9, 2019. doi: 10.1101/572636.

Petrof I, Viaene AN, Sherman SM (2015) Properties of the primary somatosensory cortex projection to the primary motor cortex in the mouse. J Neurophysiol 113:2400-2407.

Rampil IJ, Kim JS, Lenhardt R, Negishi C, Sessler DI (1998) Bispectral EEG index during nitrous oxide administration. Anesthesiology 89:671-677.

Ray S, Crone NE, Niebur E, Franaszczuk PJ, Hsiao SS (2008) Neural correlates of high-gamma oscillations $(60-200 \mathrm{~Hz})$ in macaque local field potentials and their potential implications in electrocorticography. J Neurosci 28:11526-11536.

Roopun AK, Middleton SJ, Cunningham MO, LeBeau FE, Bibbig A, Whittington MA, Traub RD (2006) A beta2-frequency $(20-30 \mathrm{~Hz})$ oscillation in nonsynaptic networks of somatosensory cortex. Proc Natl Acad Sci USA 103:15646-15650.

Schroeder KE, Irwin ZT, Gaidica M, Nicole Bentley J, Patil PG, Mashour GA, Chestek CA (2016) Disruption of corticocortical information transfer during ketamine anesthesia in the primate brain. Neuroimage 134:459-465.

Schröter MS, Spoormaker VI, Schorer A, Wohlschläger A, Czisch M, Kochs EF, Zimmer C, Hemmer B, Schneider G, Jordan D, Ilg R (2012) Spatiotemporal reconfiguration of large-scale brain functional networks during propofol-induced loss of consciousness. J Neurosci 32:12832-12840.

Schrouff J, Perlbarg V, Boly M, Marrelec G, Boveroux P, Vanhaudenhuyse A, Bruno MA, Laureys S, Phillips C, Pélégrini-Issac M, Maquet $P$, Benali $H$ (2011) Brain functional integration decreases during propofol-induced loss of consciousness. Neuroimage 57:198-205.

Shichino T, Murakawa M, Adachi T, Arai T, Miyazaki Y, Mori K (1998) Effects of inhalation anaesthetics on the release of acetylcholine in the rat cerebral cortex in vivo. Br J Anaesth 80:365-370. 
Stevens JE, Oshima E, Mori K (1983) Effects of nitrous oxide on the epileptogenic property of enflurane in cats. Br J Anaesth 55:145154.

Tadler SC, Mickey BJ (2008) Emerging evidence for antidepressant actions of anesthetic agents. Curr Opin Anaesthesiol 31:439-445.

Takeshita H, Okuda Y, Sari A (1972) The effects of ketamine on cerebral circulation and metabolism in man. Anesthesiology 36:69-75.

Thomson AM, West DC, Lodge D (1985) An N-methylaspartate receptor-mediated synapse in rat cerebral cortex: a site of action of ketamine? Nature 313:479-481.
Wang M, Yang Y, Wang CJ, Gamo NJ, Jin LE, Mazer JA, Morrison JH, Wang XJ, Arnsten AF (2013) NMDA receptors subserve persistent neuronal firing during working memory in dorsolateral prefrontal cortex. Neuron 77:736-749.

Wenzel M, Han S, Smith EH, Hoel E, Greger B, House PA, Yuste R (2019) Reduced repertoire of cortical microstates and neuronal ensembles in medically induced loss of consciousness. Cell Syst 8:467-474.e4.

Yamamura T, Fukuda M, Takeya H, Goto Y, Furukawa K (1981) Fast oscillatory EEG activity induced by analgesic concentrations of nitrous oxide in man. Anesth Analg 60:283-288. 